\title{
Specialisation versus special interest - the Australian podiatry experience
}

\author{
Ainslie Davies ${ }^{1 *}$, Paul Bennett ${ }^{1}$, Susan Nancarrow ${ }^{2}$ and Antonio Cuesta-Vargas ${ }^{1,3}$
}

\begin{abstract}
Background: Ensuring efficient and effective delivery of health care to an ageing population has been a major driver for a review of the health workforce in Australia. As part of this process a National Registration and Accreditation Scheme (NRAS) has evolved with one goal being to improve workforce flexibility within a nationally consistent model of governance. In addition to increased flexibility, there have been discussions about maintaining standards and the role of specialisation. This study aims to explore the association between practitioners' self-perceptions about their special interest in musculoskeletal, diabetes related and podopaediatric foot care and the actual podiatry services they deliver in Australia.
\end{abstract}

Methods: A cross sectional on-line survey was administered on behalf of the Australasian Podiatry Council and its' state based member associations. Self-reported data were collected over a 3-week interval and captured information about the practitioners by gender, years of clinical experience, area of work by state, work setting, and location. For those participants that identified with an area of special interest or specialty, further questions were asked regarding support for the area of special interest through education, and activities performed in treating patients in the week prior to survey completion. Queensland University of Technology Human Research Ethics approval was sought and confirmed exemption from review.

Results: 218 podiatrists participated in the survey. Participants were predominately female and worked in private practices. The largest area of personal interest by the podiatrists was related to the field of musculoskeletal podiatry $(n=65)$, followed closely by diabetes foot care $(n=61)$, and a third area identified was in the management of podopaediatric conditions $(n=26)$.

Conclusions: Health workforce reform in Australia is in part being managed by the federal government with a goal to meet the health care needs of Australians into the future. The recognition of a specialty registration of podiatric surgery and endorsement for scheduled medicines was established with this workforce reform in mind. Addition of new subspecialties may be indicated based on professional development, to maintain high standards and meet community expectations.

Keywords: Podiatry, Health workforce, Scope of practice, Diversification, Specialisation, Substitution

\section{Background}

The efficiency and effectiveness of Australia's health workforce has been under increasing scrutiny by the Australian Federal Governments' Department of Health and Ageing in responses to Australia's changing population health needs. An ageing population combined with the associated burden of chronic disease has given impetus to a growing national health workforce reform

\footnotetext{
*Correspondence: ainslie.davies@qut.edu.au

${ }^{1}$ School of Clinical Sciences, Queensland University of Technology, Brisbane, Queensland, Australia

Full list of author information is available at the end of the article
}

agenda. The 2005 Productivity Commission Report on Australia's Health workforce [1] was a major catalyst for a change in thinking about innovative ways to address this chronic burden of disease. The report recommended addressing; boundaries and arrangements that limit productivity of the health workforce, lack of the health care systems' ability to respond to communities changing needs and workforce shortages in some professions in rural and remote areas. This changing need is further evidenced by the National Health and Medical Research Council's strategic plan 2013-2015 
[2], which identifies, as a priority action, health care interventions that improve the care of patients with multiple complex chronic diseases such as diabetes and musculoskeletal disorders. With respect to the organisation and delivery of health care services, it has been noted problems exist with health care fragmentation, poor co-ordination of services, regulatory inflexibility and distortions in funding arrangements [3].

To address these issues, the Australian Health Workforce Institute (AHWI) and the Health Workforce Australia (HWA) were also established by the Council of Australian Governments (COAG) to help build a sustainable health workforce for Australia. Consequently the National Registration and Accreditation Scheme (NRAS) was implemented in 2010 to foster a competent and flexible health workforce that meets the current and future needs of the Australian community.

This paper offers the opportunity to better understand the impact these reforms are having on health professions, in particular podiatry. The purpose of this paper is to provide additional information on what scope of practice activities are undertaken in contemporary podiatry practice in Australia. This study also aims to explore the association between practitioners' self-perceptions about their special interest in musculoskeletal, diabetes related and podopaediatric foot care and the actual contemporary scope of podiatry practice in Australia.

Historically, the scope of podiatry practice in Australia was restricted to: "The diagnosis and treatment of ailments and abnormal conditions of the human foot using medical, surgical, mechanical and electrical therapies" [4].

The prevailing philosophy from COAG has been for a more unified national approach to ensuring high standards associated with the delivery of registered health care services, while being flexible enough to meet a changing community need and addressing niche markets.

In the interests of maintaining practitioners working to full scope of podiatry practice, NRAS and the United Kingdom (U.K) regulatory authority, the Health and Care Professions Council (HCPC) have adopted 'protected title' only models of governance. Any functional closure by 'scope of practice definition' would need to be prefaced on evidence that clinical outcomes were demonstrably better.

In addition to the Health Practitioner Regulation National Law, NRAS made provision for the creation of an independent national accreditation authority, the Australian and New Zealand Podiatry Accreditation Council (ANZPAC). ANZPAC's function is to assess educational programs of study in podiatry and provide an assurance those programs of study comply with standards set by the PBA.
The forces for change in professional boundaries are often driven by factors external to a profession. Nancarrow [5] described many of these forces from a health consumer perspective: changing societal expectations and beliefs, unmet demand and consumer preferences, rather than managerial changes: management philosophies and distribution of resources. This is supported by Borthwick [6], who listed marketisation as well as managerialism as drivers of change. An example of change through consumer preferences includes the incorporation of podiatric surgeon specialisation through general practitioner fund holding when fund managers were given a choice of service provider.

There is limited literature on scope of podiatric practice. One study on consumers of podiatry, examined types of patients that presented to a podiatry teaching clinic [7]. The papers concluded podiatrists see a diverse range of foot pathology across the life span of patients, and whilst skin lesions are highly prevalent there appeared to be fewer young people seeking professional podiatry care. Two articles in the British Journal of Podiatry which studied of scope of practice of podiatrists [8] and [9], identified the core work of a podiatrist involved: nail care, removal of corns and calluses and provision of footwear and footcare advice. Differences were found between the scope of practice for those working in the National Health Service (NHS) and podiatrists in private practice. Private practice podiatrists were more likely to be providing nail care, and less likely to be providing footwear advice and nail surgery. These differences in part were explained by the employment of foot care assistants in the NHS, and policies of not providing nail care to "low risk" clients.

Working to "full scope of practice" has been added to the taxonomy of allied health models of care in a recent report for Health Workforce Australia [10]. The practice of working to full scope ranks above support roles, such as the delegated activities of an allied health assistant but below advanced practice (specialist) allied health practitioners. Working within a practitioners' full scope of practice doesn't require additional training, or changes to legislation.

Conversely, extended scope of practice maybe defined as: "A discrete knowledge and skill base additional to the recognised scope of practice of a profession and/or regulatory context of a particular jurisdiction. Over time extended scope of practice may become part a professions' full scope of practice" [10]. An example of podiatric extended scope of practice is endorsement for prescribing of scheduled medicines.

To further explain the relationship between scope of practice and the concept of professional boundaries, Nancarrow and Borthwick [5] in their analysis of changing professional boundaries in the health professions undertook to divide the roles of health professionals into 
four main areas: Diversification (scope), specialisation, horizontal substitution and vertical substitution. Diversification and specialisation relate to the expansion of professional activities, usually within a discipline, e.g. recognition of surgical podiatry as a specialisation or, endorsements for prescribing of scheduled medicine for diversification. Horizontal substitution occurs when providers with a similar level of training and expertise, but different backgrounds undertake roles normally the domain of another discipline. An example of this would be: physiotherapists, chiropractors and podiatrists all prescribe foot orthotics, which was principally a podiatry domain. Vertical substitution describes the transfer of tasks to professional groups at different levels, e.g. podiatry assistants. From a practical perspective these definitions prove quite useful in understanding the interrelated roles and scopes of practice of various health professional groups. Podiatry has therefore been affected by the flexibility of professional boundaries. The likely impact being change in perceptions of status as key tasks are either delegated or enhanced through changed scope of practice.

\section{Methods}

\section{Secondary data analysis}

This paper is based on secondary data analysis from a report to the Australasian Podiatry Council taken from published survey results of member podiatrists. Queensland University of Technology Human Research Ethics approval was sought and confirmed exemption from review, exemption number 1400000791.

The design was a cross-sectional study that involved the analysis of data collected from Australian podiatrists, who represented members of the Australian Podiatry Associations. Distribution of electronic surveys occurred via the state member associations of the Australasian Podiatry Council (APodC). Responses were received from five of the six member states, excluding Western Australia. An on-line survey tool 'Survey Monkey' was used for data collection Additional file 1.

The survey obtained data with respect to the individuals; demographics, years of clinical experience, work setting (public or private sector) and work environment (solo practitioner, multi-podiatrist work team or interprofessional work team). Questions were asked of self-perception of work practice as either; 'generalist' (working to full scope of practice), 'generalist with a special interest' (extended scope of practice) or 'specialist' (reduced range, but extended scope of practice). Professional development activities were captured through participation in continuing education and professional qualifications. If practitioners considered themselves as holding a special interest in 3 or more fields of podiatry they were classified as generalist podiatrists, rather than specialists with three areas of interest. This was thought to reflect the intent of the question. Further questions were asked of those who considered themselves a specialist or held a special interest, about the area of special interest.

The area of special interest, or specialty, number of hours of continuing education spent on this area, membership of a special interest group, and tertiary qualification in the area were asked as in depth questions for those indicating a special interest or specialisation. Detailed data were obtained about the actual specific activities (treatments and patient assessment/management) that were performed in a clinical podiatry situation within the last week of practice. This important information was obtained in order to explore the association between actual and perceived scope of podiatry practice.

This study used basic descriptive statistical analysis with most data being categorical. Years of experience, and hours of working in a particular work setting, were recorded as ordinal data. The appropriate test of association between categorical variables, chi square tests using SPSS 19.0 for Windows (SPSS Inc., Chicago, IL, USA) was administered. Chi square tests can be administered when there are categories that are mutually exclusive, therefore data was arranged to reflect either being a specialist with a maximum of 2 areas of special interest or being a generalist (practicing full scope). Similarly in reviewing activities related to an area of special interest, people were classified dichotomously as either having the area of special interest (e.g. musculoskeletal) or no special interest in that area.

\section{Results}

The total sample size was 218 responses, representing $13 \%$ of the approx. 1600 population of member podiatrists who received the scope of practice survey through state based associations.

Thirty-four percent of respondents were male; This is a similar gender distribution to that reported by the Podiatry Board of Australia (PBA) in their December 2014 Podiatry Registrant Data Report on all registered podiatrists [11]. The modal group for years of experience in this study sample was $0-9$ years. The PBA reports a modal age group of 26-30 years. Both population samples represent a substantially young profession. It would appear from the data (Table 1), that about half of responding podiatrists work full time (between 33 to $40 \mathrm{~h}$ per week) on average; there were however, a large group of people in part-time employment, most of these being female.

The study participants were principally from private practice $(75 \%)$. From the survey group a majority of practitioners work in multiple podiatrist practices with up to a third working in solo practices. Multidisciplinary teams only make up a quarter of the surveyed group. Self -perception responses from survey participants were 
Table 1 Descriptive statistical results frequency analysis

\begin{tabular}{|c|c|c|c|c|c|}
\hline Characteristics & $\begin{array}{l}\text { Self - perceived } \\
\text { generalist }(n=96)\end{array}$ & $\begin{array}{l}\text { Self - perceived } \\
\text { specialist }(n=114)\end{array}$ & Totals & Percentage & Analysis \\
\hline \multicolumn{6}{|l|}{ Gender } \\
\hline Female & 70 & 68 & 138 & $66 \%$ & \\
\hline Male & 26 & 46 & 72 & $34 \%$ & ChiSq $(\mathrm{df}=1, P=0.044)$ \\
\hline Missing & & & 8 & & \\
\hline \multicolumn{6}{|l|}{ Years experience } \\
\hline $0-9$ years & 24 & 50 & 74 & $34 \%$ & \\
\hline $10-19$ years & 27 & 32 & 59 & $27 \%$ & \\
\hline $20-29$ years & 25 & 23 & 48 & $22 \%$ & \\
\hline $30-39$ years & 7 & 19 & 26 & $12 \%$ & \\
\hline $40+$ years & 6 & 5 & 11 & $5 \%$ & ChiSq $(\mathrm{df}=2, P=0.142)$ \\
\hline \multicolumn{6}{|l|}{ Location } \\
\hline Urban & 64 & 61 & 128 & $58 \%$ & \\
\hline Rural and remote & 18 & 18 & 38 & $17 \%$ & ChiSq $(\mathrm{df}=1, P=0.899)$ \\
\hline Missing & & & 52 & $24 \%$ & \\
\hline \multicolumn{6}{|c|}{ What is your primary work setting? } \\
\hline Private practice & 82 & 81 & 163 & $75 \%$ & \\
\hline Public sector & 11 & 31 & 42 & $19 \%$ & \\
\hline Education & 0 & 3 & 3 & $1 \%$ & \\
\hline Missing & & & 10 & $5 \%$ & \\
\hline \multicolumn{6}{|c|}{ Primary work environment } \\
\hline Multipod & 42 & 44 & 88 & $40 \%$ & \\
\hline Solo pod & 35 & 33 & 71 & $32 \%$ & \\
\hline MDT & 17 & 37 & 55 & $25 \%$ & ChiSq $(\mathrm{df}=3, P=0.103)$ \\
\hline Missing & & & 4 & $2 \%$ & \\
\hline \multicolumn{6}{|l|}{ Work hours } \\
\hline Part-time & 50 & 51 & 111 & $51 \%$ & \\
\hline Full-time & 35 & 62 & 97 & $44 \%$ & ChiSq $(\mathrm{df}=1, P=0.190)$ \\
\hline Missing & & & 10 & $5 \%$ & \\
\hline
\end{tabular}

distributed between generalists $(n=96)$ generalists with a special interest $(n=107)$ and specialist $(n=15)$. Self-perception of specialist/one to two special interests status was compared with gender, years of experience, location, primary work environment and clinical practice.

For practitioners who declared a specialty or special area of interest further questions were asked of these subsets. There were two areas of special interest with very similar group sizes: Sports and biomechanics $(n=65)$ and Diabetes $(n=63)$. Analysis was performed for a relationship for categorical variables using Chi square tests, $\alpha$ level of significance (0.05), degrees of freedom (df) are as tabled. Comparisons were made within the biomechanics specialist group to find if there were activities that adequately described a podiatrist with a special interest in biomechanics.
There were many activities that are related to self -perception of biomechanics specialist see Table 2. The most significant activities were conveyed through Chi square analysis $(\mathrm{df}=1, P=0.0000)$ performed by those with a special interest in sport/biomechanics. These activities were: use of computer aided design and computer aided manufacture (CADCAM) orthoses, use of heel lifts, request for ultrasound, performing foot mobilisation, using a 3D scan technique in orthotic manufacture. Similarly there were activities that podiatrists performed that distinguished them as specialists in the diabetic foot, such as wound debridement, pathology for a wound swab and total contact cast see Table 3. The work environment and work setting were influential in perceptions of specialist status. See Table 4.

Work environment with regards to sector was significant with biomechanics specialists' predominately in private 
Table 2 Analysis of special interest area

\begin{tabular}{|c|c|c|c|c|}
\hline & $\begin{array}{l}\text { No special interest in } \\
\text { sports/biomechanics }(n=152)\end{array}$ & $\begin{array}{l}\text { Special interst in } \\
\text { sports/biomechanics }(n=65)\end{array}$ & & \\
\hline Activity performed by practitioner & Number & Number & Total for each activity & Analysis \\
\hline Use of CADCAM orthoses & 18 & 24 & 42 & * \\
\hline Use of heel lift & 71 & 51 & 122 & * \\
\hline Request ultrasound & 54 & 41 & 95 & * \\
\hline Perform foot mobilisation & 23 & 27 & 50 & * \\
\hline 3D scan & 15 & 20 & 35 & * \\
\hline Refer to orthopaedic surgeon & 46 & 35 & 81 & $* *$ \\
\hline Customised non-cast orthoses & 68 & 46 & 114 & $* *$ \\
\hline Gait assessment and report & 85 & 53 & 138 & $* *$ \\
\hline Refer for x-ray & 91 & 54 & 145 & $* * *$ \\
\hline Custom orthoses & 74 & 43 & 117 & $* * * *$ \\
\hline Totals & 152 & 65 & & \\
\hline
\end{tabular}

Chi Square tests all had $\mathrm{df}=1,{ }^{*} P=0.000,{ }^{* *} P=0.001,{ }^{* * *} P=0.002,{ }^{* * * *} P=0.025$

practice ChiSq $(\mathrm{df}=2, P=0.003)$. Podiatrists with a special interest in Diabetes were more aware of their special interest/specialisation when working in the public sector, ChiSq $(\mathrm{df}=2, P=0.000)$ and a multi-disciplinary team environment: ChiSq ( $\mathrm{df}=3, P=0.000)$.

\section{Discussion}

\section{Characteristics of a specialist podiatrist}

This paper evaluates the perceptions and attributes of practitioners' with a full scope of practice (generalist) compared with podiatrist who have a special interest or self perceived (specialist) scope of practice. Table 1 illustrates when practitioners are asked to categorise themselves to be either 'generalist' or 'specialist/generalist with a special interest' or 'specialist' podiatrist, male gender was identified as being the only factor which would predict perception of status (Chi square, df $=1, P=0.044)$. In this study the lesser proportion (34 \%) of participants were male, however $64 \%$ considered themselves to be specialists or working in an area of special interest. This may reflect more males being in the full-time workforce for longer periods. Exploring gender differences would be a good area for further research. Self -perception of specialist status was not explained by the variables: years of experience, location, working in rural versus urban environment, state worked in, or part-time/full-time work status.

Currently there is only one area of specialisation recognised by the Podiatry Board of Australia: podiatric surgery with the protected title of podiatric surgeon. A person must have worked as a generalist registered podiatrist for 2 years prior to pursuing an approved program of study. Fellowship of the Australian College of Podiatric Surgeons is gained through 3 years full time study. Alternatively the Doctor of Clinical Podiatry program is available through the University of Western Australia. All Australian University graduates from podiatry degrees (except unaccredited courses) now have sufficient qualification to meet the requirements of the Podiatry Board of Australia for endorsement for scheduled medicines.

As podiatric scope expands in Australia to recognise the specialty of podiatric surgery and endorsement for prescribing rights; it will be interesting to re-evaluate practitioners views on scope of practice in the future and whether this extended scope of practice is truly a new descriptor for future podiatrists scope of practice

Table 3 Analysis of special interest area. An anlaysis of 'Diabetes' as an area of special interest

\begin{tabular}{|c|c|c|c|c|}
\hline & No special interest in diabetes & Special interest in diabetes & & \\
\hline Activity performed by practitioner & Number $(n=151)$ & Number $(n=63)$ & Totals & Analysis \\
\hline Wound debridement & 92 & 56 & 214 & * \\
\hline Pathology swab & 5 & 14 & 19 & * \\
\hline Ankle brachial index & 29 & 24 & 53 & $* *$ \\
\hline X-ray & 97 & 48 & 145 & $* * *$ \\
\hline Totals & 151 & 63 & & \\
\hline
\end{tabular}

Chi Square tests all had df $=1,{ }^{*} P=0.000,{ }^{* *} P=0.002,{ }^{* * *} P=0.054$ 
Table 4 Relationship of special interest to work. An exploration of two specific situations, primary work setting and primary work environment

\begin{tabular}{|c|c|c|c|c|}
\hline Primary work setting & Private sector $(n=163)$ & Public sector $(n=42)$ & Totals & Analysis \\
\hline Biomechanics special interest & 61 & 4 & 65 & Chi Sq $(\mathrm{df}=2, P=0.003)$ \\
\hline Diabetes special interest & 35 & 28 & 63 & Chi Sq $(\mathrm{df}=2, P=0.000)$ \\
\hline Podopaediatrics special interest & 20 & 6 & 26 & Chi Sq $(\mathrm{df}=2, P=0.690)$ \\
\hline Primary work environment & Multi-podiatrists $(n=86)$ & Multi-disciplinary team $(n=54)$ & Solo podiatrist & Analysis \\
\hline Biomechanics special interest $(n=65)$ & 32 & 13 & 20 & Chi Sq $(\mathrm{df}=2, P=0.217)$ \\
\hline Diabetes special interst $(n=63)$ & 14 & 28 & 21 & Chi Sq $(\mathrm{df}=2, P=0.000)$ \\
\hline
\end{tabular}

$[12,13]$. The question arises: is measuring 'specialisation or special interest', simply a quasi marker for professional status [14]?

The only activity that adequately described a 'specialist interest' categorised podiatrist was the request for $\mathrm{x}$-rays, not the similar activity of requesting diagnostic ultrasound. This is mostly explained by the two most shared areas of special interest: biomechanics/sports and diabetes/high risk foot both frequently requiring $\mathrm{x}$-ray to assist diagnosis, but for different presentations or conditions.

\section{Analysis of specialisation area}

Those participating clinicians who described themselves as a specialist or have a special interest in sports/biomechanics were characterised by being in the private sector and not by the work environment- of being in a multi-podiatrist practice- (see Table 4). There were also podiatric practise activities undertaken that characterised this area of special interest, such as three dimensional foot scan, Computer aided design- CADCAM orthoses, custom orthoses, customised non-cast orthoses, use of heel lift, performing foot mobilisation, request of ultrasound and $\mathrm{x}$-ray and refer to orthopaedic surgeon. The development of skills in biomechanics appears to be part of working to full scope of practice for Australian podiatrists, however Kraus suggests this may be a diminishing scope of practice in young practitioners in the United States of America [15, 16]. The cultural context of health service delivery appears to influence pursuit of opportunity and rewards of specialisation.

Awareness of special interest in diabetes or the highrisk foot appears to be heightened by work setting in public sector and working in a multi-disciplinary team in Australia- (see Table 4). This awareness more closely resembles the work environment in the United Kingdom's NHS and the development of specialisms [17]. The Australian experience of working in a multi-disciplinary team presents some likely challenges to professional boundaries. This is more likely to be the case in the public sector than private where roles around wound care and diabetes are defined by authorisations and work capacity $[5,18,19]$.

Activities that were statistically significant for those with a special interest in diabetes/high risk foot at the $P=0.05$ level for Chi-square tests were: wound debridement, pathology swab, total contact cast, taking of ankle-brachial index (ABI) and requests for $\mathrm{x}$-ray. This raises the question as to whether these activities are within the scope of a generalist podiatrist and more frequent performing of these activities is associated with special area of interest or whether additional training is required to recognise an increased skill set.

\section{Future scope of practice in Australia}

The future scope of practice in podiatry is dependent on external factors such as government legislation, funding for training, population ageing and demand for services, particularly with chronic disease and medical dominance of the health system. The Health workforce of the future according to the National Health Workforce Innovation and Reform Strategic Framework 2011-2015 should:

"Develop an adaptable health workforce equipped with the requisite competencies and support that provides team-based and collaborative models of care" [20].

This model is contrary to traditional status gaining roles of specialisation which we have shown are still pursued within the podiatry profession in Australia. Will the proposed future model of collaborative care facilitate professional satisfaction and will it be embraced by podiatry, which is principally managed by private practitioners?

Internal drivers will be determined from within the professional body and are subject to external influences. The future will involve promoting the status of the profession through recognition by role extension and task substitution to gain the full scope of practice. Future difficult negotiations and interaction with other health professionals in an inter-professional manner will determine boundary negotiation [14, 21-23]. 


\section{Study limitation}

This study was originally designed as an industry lead review and thus questions were formatted in a particular way to elicit these responses. This has produced some recall and information bias, with some small sample groups, which were too small for Chi-square analysis. In comparisons between 'generalist' and 'specialist', groups were combined into 'specialist' if they either called themselves 'specialist' or had a special interest in one or two areas, thus making the groups more dichotomous. The population sample was limited by distribution of the survey, with an uneven uptake by only $13 \%$ of the profession. The sample size was only 218 interested respondents and is a clear limitation to the study, which was undertaken through voluntary responses of members of the APodC. This still remains a timely report on the current state of the profession at a critical time of change with recent introduction of specialisation and national registration.

\section{Conclusion}

It is clear that the Australian health workforce is undergoing change, responding to health consumer population and demographic forces and government priorities. Regulation of health professions in Australia has fundamentally shifted from a state based to nationalised system and one of protectionism of scope to protection of title only.

Podiatry Board of Australia has acknowledged the need for recognition of podiatric surgeon as a specialist category, yet many other practitioners relate to the term specialist or have a special interest within podiatry. It is suggested that recognition of specialisation is different for regularity authorities to practicing podiatric clinicians. Regularity authorities recognising public safety as a key determinant of need for specialisation, however practicing clinicians awareness of specialistisation is related to gender, work environment and setting and is associated with performing of a number of treatment related activities. This is in direct contrast to government agencies such as Health Workforce Australia who encourage fostering of generalist skills, and delivery of care through collaboration and innovation to meet the health care needs of all Australians.

Health workforce reform in Australia is driven principally by factors external to the profession that affects the entire health workforce. The podiatry profession in Australia is different to most other health professions in being principally private practice, not working in multi-disciplinary teams, being young, female biased and pursuing specialist areas of interest.

\section{Availability of supporting data}

Original data are available on request to the corresponding author.

\section{Additional file}

Additional file 1: Original scope of practice electronic survey. (DOCX $39 \mathrm{~kb}$ )

\section{Abbreviations}

AHPRA: Australian health practitioner regulation agency; AHWI: Australian health workforce institute; ANZPAC: Australia and New Zealand accreditation council; COAG: Councils of Australian governments; HWA: Health workforce Australia; NHS: National health service; NRAS: National registration and accreditation scheme; PBA: Podiatrists board of Australia.

\section{Competing interests}

The first author was the project manager on the original project who received payment for presenting 2 stages of the project. The first author has since become a director of the Australasian Podiatry Council. The second author is a director with the Podiatry Board of Australia.

\section{Authors' contributions}

The first author AD per the background research, collected and interpreted the data and compiled the original report. PB assisted with interpreting the data and compiling the journal manuscript. ACV made contributions in study design and international comparisons. SN assisted in draft manuscript comments. All authors read and approved the final manuscript.

\section{Acknowledgements}

The survey was commissioned by the Australasian Podiatry Council with the final aim of promoting the contemporary scope of podiatrists in Australia.

\section{Author details}

${ }^{1}$ School of Clinical Sciences, Queensland University of Technology, Brisbane, Queensland, Australia. ${ }^{2}$ Southern Cross University, Lismore, New South Wales, Australia. ${ }^{3}$ University of Malaga, Malaga, Spain.

Received: 29 April 2015 Accepted: 26 November 2015

Published online: 03 December 2015

\section{References}

1. Australia. Productivity Commission. Australia's health workforce: productivity commission research report. Melbourne: Productivity Commission; 2005.

2. NHMRC, 2012 National Health and Medical Research Council Strategic Plan [internet] Published December 2012. Publication reference NH160. cited 112-2015. Available from https://www.nhmrc.gov.au/guidelines-publications/ nh160.

3. Purcell J, Dennis P. Shaping Australia's health workforce. Aust Health Consume. 2005;2(2005-2006):17-8.

4. Government Q. Podiatrists Act, 1969. Brisbane: 1969.

5. Nancarrow SA, Borthwick AM. Dynamic professional boundaries in the healthcare workforce. Sociol Health IIIness. 2005;27(7):897-919. doi:10.1111/j.1467-9566.2005.00463.x.

6. Borthwick AM. Challenging medicine: the case of podiatric surgery. Work Employ Soc. 2000;14(2):369-83. doi:10.1177/09500170022118455.

7. Bennett PJ. Types of foot problems seen by Australian podiatrists. Foot. 2012;22(1):40-5. doi:10.1016/j.foot.2011.11.002.

8. Farndon L, Vernon W, Potter J, Parry A. The professional role of the podaitrist in the new Millenium: An analysis of current practice. Paper 1. British J Podiatry. 2002;5(3):68-72.

9. Farndon L, Vernon W, Potter J, Parry A. The Professional role of the podiatrist in the new Millenium: is there a gap between professional image and scope of practice? Paper 2. British J Podiatry. 2002;5(4):100-2.

10. Health Workforce Australia. Queensland Health Practitioners' Models of Care project: evaluation learning and upscaling of results for a national audience. Final report. January 2014. cited 1-12-2015. Available from http://www.hwa. gov.au.

11. Podiatry Board of Australia. Podiatry Registrant Data: AHPRA April 2013 Newsletter. Sighted 03/03/2014 at http://www.podiatryboard.gov.au/News/ Newsletters.aspx

12. Borthwick AM, Short AJ, Nancarrow SA, Boyce R. Non- medical prescribing in Australasia and the UK: the case of podiatry. J Foot Ankle Res. 2010;3(1):1. doi:10.1186/1757-1146-3-1. 
13. Gilheany MF, Borthwick AM. Recent developments in podiatric prescribing in the UK and Australia. J Foot Ankle Res. 2009;2:37. doi:10.1186/1757-1146-2-37.

14. Mandy P. The status of podiatry in the United Kingdom. Foot (Edinb). 2008;18(4):202-5. doi:10.1016/j.foot.2008.05.003.

15. Kraus J. Is podiatry turning away from biomechanics? There is evidence that the profession may be relinquishing its leadership role in this vital core competency. Podiatry Manage. 2011;30(7):115.

16. Payne CB. The past, present, and future of podiatric biomechanics. J Am Podiatr Med Assoc. 1998;88(2):53.

17. Bacon, D. Charismatic authority in modern healthcare: the case of the 'diabetes specialist podiatrist'. Social Health IIIn. 2013;35 (7). doi:10.1111/1467-9566.1-2024.

18. Corbett LQ. Wound care nursing: professional issues and opportunities. Advances Wound Care. 2012;1(5):189-93. doi:10.1089/wound.2011.0329.

19. Suen CF. Li Wai D, Aw HC, Eldho P, La Wong J. Evaluation of an Australian multidisciplinary diabetes support clinic. The Internet Journal of Endocrinology. 2012;7(1).Published 3 August 2012. Found at: http://sf5mc5tj5v.search.serialssolutions.com/?ctx_ver=Z39.88-2004\&ctx_ enc=info\%3Aofi\%2Fenc\%3AUTF-8\&rfr_id=info:sid/summon.serialssolutions. com\&rft_val_fmt=info:ofi/fmt:kev:mtx:journal\&rft.genre=article\&rft. atitle=Evaluation+of+an+Australian+multidisciplinary+diabetes+support + clinic\&rft.jtitle=The+Internet+08-03\&rft.pub=Internet+Scientific +Publications+LLC\&rft.issn=1540-2606\&rft.volume $=7 \&$ rft.issue $=1 \&$ rft. externalDBID=n\%2Fa\&rft.externalDoc|D=302112585.

20. Health Workforce Australia. National Health Workforce Innovation and Reform Strategic Framework for Action 2011-2015. cited 1-12-2015. Available from www.hwa.gov.au/resources/publications.

21. Skipper JK, Hughes JE. Podiatry: A Medical care specialty in quest of full professional status and recognition. Soc Sci Med. 1983;17(20):1541-8.

22. Vernon W, Borthwick AM, Farndon L, Nancarrow SA, Walker J. Issues of podiatry status in the UK. British J Podiatry. 2005;8(1):6-10.

23. Borthwick AM, Nancarrow SA, Vernon W, Walker J. Achieving professional status: Australian podiatrists' perceptions. J Foot Ankle Res. 2009;2(1):4. doi:10.1186/1757-1146-2-4.

\section{Submit your next manuscript to BioMed Central and we will help you at every step:}

- We accept pre-submission inquiries

- Our selector tool helps you to find the most relevant journal

- We provide round the clock customer support

- Convenient online submission

- Thorough peer review

- Inclusion in PubMed and all major indexing services

- Maximum visibility for your research 